Purity estimation of seized stimulant-type new psychoactive substances without reference standards by nitrogen chemiluminescence detection combined with GC-APCI-QTOFMS

\title{
Mesihää, Samuel
}

2020-07

Mesihää , S , Rasanen , I \& Ojanperä , I 2020 , ' Purity estimation of seized stimulant-type new psychoactive substances without reference standards by nitrogen chemiluminescence detection combined with GC-APCI-QTOFMS ' , Forensic Science International , vol. 312 , 110304 . https://doi.org/10.1016/j.forsciint.2020.110304

http://hdl.handle.net/10138/329505

https://doi.org/10.1016/j.forsciint.2020.110304

cc_by_nc_nd

acceptedVersion

Downloaded from Helda, University of Helsinki institutional repository.

This is an electronic reprint of the original article.

This reprint may differ from the original in pagination and typographic detail.

Please cite the original version. 


\section{Journal Pre-proof}

Purity estimation of seized stimulant-type new psychoactive substances without reference standards by nitrogen chemiluminescence detection combined with GC-APCI-QTOFMS

Samuel Mesihää (Conceptualization) (Formal analysis)

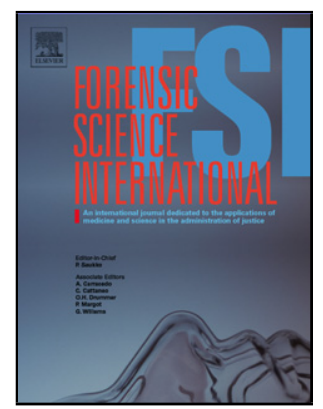

(Methodology) (Writing - original draft), Ilpo Rasanen

(Methodology), Ilkka Ojanperä (Conceptualization) (Supervision)

(Writing - review and editing)

PII:

S0379-0738(20)30166-3

DOI:

https://doi.org/10.1016/j.forsciint.2020.110304

Reference:

FSI 110304

To appear in:

Forensic Science International

Received Date: $\quad 24$ January 2020

Revised Date: $\quad 11$ April 2020

Accepted Date: $\quad 21$ April 2020

Please cite this article as: Mesihää S, Rasanen I, Ojanperä I, Purity estimation of seized stimulant-type new psychoactive substances without reference standards by nitrogen chemiluminescence detection combined with GC-APCI-QTOFMS, Forensic Science International (2020), doi: https://doi.org/10.1016/j.forsciint.2020.110304 
This is a PDF file of an article that has undergone enhancements after acceptance, such as the addition of a cover page and metadata, and formatting for readability, but it is not yet the definitive version of record. This version will undergo additional copyediting, typesetting and review before it is published in its final form, but we are providing this version to give early visibility of the article. Please note that, during the production process, errors may be discovered which could affect the content, and all legal disclaimers that apply to the journal pertain.

(C) 2020 Published by Elsevier. 


\section{Purity estimation of seized stimulant-type new psychoactive substances without reference standards by nitrogen chemiluminescence detection combined with GC-APCI-QTOFMS}

Samuel Mesihää ${ }^{\mathrm{a}^{*}}$, Ilpo Rasanen ${ }^{\mathrm{b}}$, Ilkka Ojanperä ${ }^{\mathrm{a}, \mathrm{b}}$

${ }^{\text {a }}$ University of Helsinki, Department of Forensic Medicine, PO Box 40, FI-00014 University of Helsinki, Finland

${ }^{\mathrm{b}}$ Finnish Institute for Health and Welfare, Forensic Toxicology Unit, PO Box 30, FI-00271 Helsinki, Finland

* Corresponding author. Email address: samuel.mesihaa@helsinki.fi

\section{Highlights}

- Reference standards for new psychoactive substances (NPS) are not readily available

- Nitrogen chemiluminescence detection (NCD) possesses equimolar response to nitrogen

- GC-NCD allowed purity estimation of stimulant NPS with only two external calibrators

- The grand mean equimolarity of twenty-eight stimulants studied was $91.9 \%$

- This platform is potentially applicable to instant purity assessment of seized NPS 


\begin{abstract}
Purity assessment of seized material containing new psychoactive substances (NPS) is complicated without appropriate primary reference standards. Here we present a method for fast quantitative estimation of stimulant-type NPS with use of secondary reference standards, based on gas chromatography nitrogen chemiluminescence detection coupled with atmospheric pressure chemical ionization quadrupole time-offlight mass spectrometry (GC-NCD-APCI-QTOFMS). Quantification was based on the detector's $N$ equimolar response to nitrogen and using two external nitrogen-containing calibrators, MDMA for prim- and sec- amines and $\alpha$-PVP for tert- amines. Sample preparation involved dissolving the seized powdery material in an organic solvent mixture followed by acylation with $\mathrm{N}$-methyl-bis-trifluoroacetamide (MBTFA). The method's between-day accuracy and precision over a five-day period was measured for twenty-eight stimulants: the grand mean equimolarity was $91.9 \%$ (CV 5.5\%), as compared with primary reference standards. The GC-NCD-APCI-QTOFMS method was applied to the purity estimation of forty-two seized powder samples previously found to contain stimulant-type NPS by appropriate methods. The quantitative results were compared to those obtained by an established method relying on liquid chromatography chemiluminescence detection (LC-CLND), the latter using caffeine as an external calibrator. The mean difference of purity values between the methods was $8.1 \%$ (range $0.4-26.7 \%$ ). The presented method might find use as a tool for instant purity assessment in forensic laboratories.
\end{abstract}

\title{
Keywords
}

Seized drugs

New psychoactive substances

Illicit stimulants

Reference standard

Nitrogen chemiluminescence detection

Time-of-flight mass spectrometry

\section{Introduction}

Many new psychoactive substances (NPS) are marketed as legal alternatives to replace prohibited drugs of abuse but limited and misleading information regarding to content, purity and pharmacological properties of the sold NPS have been associated with harmful effects for health which may in some cases lead to fatalities $[1,2]$. The last two decades have shown continuous emergence of NPS on the European illicit drug market: between years 1997 and 2018, more than 730 NPS were reported through the EU Early Warning System [2]. Reference standards are normally required for the identification and quantification of toxicologically relevant 
substances. However, the increasingly high number of different NPS is driving forensic laboratories either to a tedious and costly process of acquiring reference standards from various sources or to a decision of letting the quantity of NPS undetermined $[3,4]$.

Much attention has been paid to the development of efficient identification methods for NPS in seized samples and biological material. The advent of bench-top high-resolution mass spectrometry (HR-MS) and soft ionization techniques, such as electrospray ionization (ESI) and atmospheric pressure chemical ionization (APCI), has allowed detection of compounds based on their molecular formula by targeting the intact precursor ion with high mass accuracy. The advantage over traditional low-resolution mass spectrometry is that HR-MS enables molecular formula-based identification of drugs, which has been applied to tentative identification of NPS [5]. Molecular formula-based identification is more reliable when it involves also molecular fragmentation data [6], which can today be achieved through international collaboration, for example using a crowd-sourced online NPS database that supports multiple vendor platforms [7].

Quantitative HR-MS without reference standards is an attractive concept because of the capability to determine a vast number of compounds in a non-targeted manner. Many fields of analysis, such as forensic toxicology, environmental analysis, safety testing of pharmaceutical drug metabolites and biomarker screening would likely benefit from such an analytical approach. However, quantification without primary reference standards by MS-based techniques is not viable because ionization in MS is structure-dependent, and it is affected by external factors, such as $\mathrm{pH}$ and matrix interferences [8]. Hatsis et al. [9] explored the use of secondary reference standards in ESI-HR-MS and estimated drug metabolite concentrations from the parent drug ion responses, but they concluded that the applications were limited due to low accuracy. In their study, the response ratios for 45 metabolite-parent drug pairs ranged from 0.014 to 8.6, which signifies up to 71-fold difference in the quantitative result.

Nuclear magnetic resonance spectroscopy (NMR) is a qualified technique for both qualitative and quantitative analysis of seized materials [10,11], but this technique is not achievable for all laboratories. Recently, a new tool has emerged for the rapid quantitative estimation of NPS in blood samples using secondary reference standards [12,13]. In the latest application, Mesihää et al. (2019) have described a method for simultaneous detection and quantitative estimation of illicit psychostimulants in blood, based on gas chromatography nitrogen chemiluminescence detection coupled with atmospheric pressure chemical ionization quadrupole time-of-flight mass spectrometry (GC-NCD-APCI-QTOFMS) [12]. Quantitative estimation relied on the NCD's $N$-equimolar response to nitrogen, using amphetamine, 3,4-methylenedioxymethamphetamine (MDMA) and methylenedioxypyrovalerone (MDPV) as external calibrators for prim-, sec- and tert- amines, respectively.

There is an equally strong demand for the instant purity assessment of NPS -related seizures in the absence of primary reference standards. Consequently, in this study we extend the scope of the previously developed GCNCD-APCI-QTOFMS method to seized samples containing stimulant-type NPS, applying a facile procedure 
for sample preparation. Furthermore, we compare the quantitative results to those obtained by an established single-calibrator method relying on liquid chromatography - chemiluminescence nitrogen detection (LCCLND).

\section{Material and methods}

\subsection{Chemicals}

Reference standards of pharmaceutical-grade purity were obtained from the following suppliers: 2C-B, $2 \mathrm{C}-\mathrm{T}$ 4, 3,4-dimethoxyphenethylamine (DMPEA), 3,4-methylenedioxy- $N$-methyl- $\alpha$-ethylphenethylamine (MBDB), 4-methylamphetamine, 4-methylthioamphetamine (4-MTA), MDDMA and mescaline were from Lipomed (Arlesheim, Switzerland). 2-Fluoroamphetamine, 4-methylethcathinone, $\alpha$-PHP, methylone, pentedrone, PV8 and $\alpha$-ethylaminopentiophenone were from Cayman Chemical (Ann Arbor, MI, USA). 4Methylmethamphetamine (4-MMA), meta-chlorophenylpiperazine ( $m \mathrm{CPP}$ ) and MDMA were from National Measurement Institute (Pymble, Australia). 3-Fluorophenmetrazine, 4-fluoro- $\alpha$-PVP, MDPV and $\alpha$-PVP were from Chiron (Trondheim, Norway). 5,6-Methylenedioxy-2-aminoindane (MDAI), butylone, camfetamine, dibutylone, ethylphenidate and methiopropamine were from LGC GmbH (Luckenwalde, Germany). BromoDragonFLY was from Toronto Research Chemicals (Toronto, ON, Canada). Cocaine was from Sigma Aldrich (St Louis, MO, USA). Buspirone was from Orion Corporation (Espoo, Finland). Seized samples were received from the National Bureau of Investigation, Finland, and from the Finnish Customs Laboratory. All seized samples were assumed to exist as their hydrochloride $(\mathrm{HCl})$ form.

Derivatization reagent, $\mathrm{N}$-methyl-bis-trifluoroacetamide (MBTFA) was from Thermo Fischer Scientific (Bellefonte, PA, USA).

\subsection{External calibrators}

MDMA was used as an external calibrator in GC-NCD for prim- and sec-amines, and $\alpha$-PVP for tertiary amines. In quantitative estimation by GC-NCD, a linear regression model was constructed with an appropriate external calibrator using concentrations $20,50,100,200$ and $500 \mu \mathrm{g} / \mathrm{mL}$ with three replicates. The peak area of the compounds, with two replicates each, was corrected according to the relative nitrogen content prior to applying the linear regression model. All peak areas were normalized to the peak area of the internal standard buspirone. The lowest calibration point from a $20 \mu \mathrm{g} / \mathrm{mL}$ working solution corresponded to 0.65 and $0.55 \mathrm{ng}$ of nitrogen injected for MDMA and $\alpha$-PVP, respectively.

\subsection{Sample preparation}

The sample preparation procedure was adapted from Meng and Margot [14], but using simple MBTFA acylation instead of dual derivatization. Briefly, 2-3 mg of the reference standards or seized powdery material was dissolved in chloroform/pyridine (5:1) to obtain a stock solution with an apparent concentration of 1000 
$\mu \mathrm{g} / \mathrm{mL}$. The stock solution was further diluted to obtain a working solution that contained $200 \mu \mathrm{g} / \mathrm{mL}$ each of the 4-5 different reference standards, an external calibrator or seized material. Buspirone was dissolved in chloroform/pyridine (5:1) to obtain an internal standard solution containing $200 \mu \mathrm{g} / \mathrm{mL}$ of buspirone. Subsequently, $250 \mu \mathrm{L}$ of the internal standard solution was mixed with $250 \mu \mathrm{L}$ of the working solution. Derivatization was accomplished by adding $50 \mu \mathrm{L}$ of MBTFA to this mixture, after which the solution was briefly mixed and heated for 30 minutes at $70{ }^{\circ} \mathrm{C}$.

\subsection{GC-NCD-APCI-QTOFMS}

The instrument conditions were essentially similar to those described earlier [12] with minor modifications.

The GC was operated in the split injection mode (formerly [12] in the splitless mode) at ratio of 10:1. The injector port temperature was $250^{\circ} \mathrm{C}$ and the transfer line temperature $320^{\circ} \mathrm{C}$. The injection volume was 1.0 $\mu \mathrm{L}$. The oven temperature was initially held at $80^{\circ} \mathrm{C}$ and then increased by $30^{\circ} \mathrm{C}$ per min to $280^{\circ} \mathrm{C}$ and at the rate of $10^{\circ} \mathrm{C}$ per min to $320^{\circ} \mathrm{C}$, which was held for $4 \mathrm{~min}$. Helium was used as carrier gas at $1 \mathrm{~mL} / \mathrm{min}$ in the constant flow mode.

The QTOFMS was operated in the APCI positive ionization mode. Mass acquisition was performed in All Ions mode, and data were recorded over the $\mathrm{m} / \mathrm{z}$ range of 50-450 with an acquisition rate of $5 \mathrm{spectra} / \mathrm{s}$. Collision energy at the low energy function was $0 \mathrm{eV}$, whereas in the high energy function $22 \mathrm{eV}$ was used. A mass increment of $95.9823 \mathrm{Da}$ was added to the theoretical mass of each MBTFA reaction product. All data were collected and analyzed with MassHunter Data Acquisition B.04.00 and MassHunter Qualitative analysis B.07.00. software (Agilent Technologies).

\section{5. $L C-C L N D$}

The reference method utilizing LC-CLND coupled with UV diode array detector for the analysis of seized NPS samples was previously described by Rasanen et al. [15]. In this method caffeine was used as an external calibrator.

\section{Results and discussion}

\subsection{Peak identification}

Peak identification was based on the known molecular structure and the corresponding accurate mass of the precursor ion $[\mathrm{M}+\mathrm{H}]^{+}$. Detection of the precursor ion by GC-APCI-QTOFMS scan mode was used to verify successful derivatization and to prove peak identity in subsequent quantitative GC-NCD analysis.

The acylation of stimulants by MBTFA expectedly increased the mass of the precursor ion by $95.9823 \mathrm{Da}$ for each prim- or sec-amine. In GC-APCI-QTOFMS, the protonated molecule was retained with all twenty-eight 
reference standards and with all forty-two NPS in seized samples. Incomplete derivatization was observed only with methoxetamine and 5-MeO-MIPT in seized samples. For methoxetamine, $m / z 344.1468$ and $m / z 248.1645$ were found, and for 5-MeO-MIPT, $m / z 343.1628$ and $m / z 247.1805$ were found, corresponding to a mixture of underivatized and derivatized product in each case. These two drugs were subsequently measured without MBTFA derivatization using the external calibrator for tert- amines ( $\alpha$-PVP), which resulted in a single peak with consistent shape in each case.

Simple MBTFA acylation of amino groups instead of dual derivatization was carried out here, unlike in the original study [14], because constituent profiling was not an objective. Chloroform was used as a reagent in sample preparation as per the original study, due to its indispensable chemical properties as a solvent. Appropriate caution should be taken to avoid exposure to this toxic chemical.

\subsection{Equimolarity of GC-NCD using external secondary calibrators}

Table 1 shows the between-day accuracy and precision of GC-NCD quantification, using secondary reference standards, for the twenty-eight pure stimulants studied at $200 \mu \mathrm{g} / \mathrm{mL}$ level. The grand mean equimolarity was 91.9\% (CV 5.5\%), as compared with primary reference standards. Table 2 shows, based on the same experimental setting, that the grand mean equimolarity over a concentration range of $40-200 \mu \mathrm{g} / \mathrm{mL}$ was $89.8 \%$ (CV 7.5\%) and the bias of individual equimolarity measurements was always better than 30\%, except for methylone and cocaine. There was little difference between the results across the concentration range.

Table 1. Between-day equimolarity and precision for stimulant-type NPS reference standards by GC-NCD a.

\begin{tabular}{lccccc} 
Analyte & $\begin{array}{c}\text { Mean } \\
\text { equimolarity (\%) }\end{array}$ & $\begin{array}{c}\text { Median } \\
\text { equimolarity (\%) }\end{array}$ & CV (\%) & Range (min-max) \\
\hline Primary amines & & & & & \\
External calibration with MDMA & & & 6.8 & 79.7 & 95.6 \\
2C-B & 88.7 & 89.2 & 4.5 & 77.9 & 86.7 \\
2C-T-4 & 82.9 & 83.8 & 4.1 & 76.7 & 84.1 \\
2-Fluoroamphetamine & 81.0 & 81.8 & 5.3 & 90.8 & 104.8 \\
4-Methylamphetamine & 99.3 & 99.5 & 7.1 & 85.4 & 99.6 \\
4-Methylthioamphetamine & 91.0 & 87.1 & 4.1 & 76.8 & 85.6 \\
Bromo-DragonFLY & 82.6 & 83.6 & 5.7 & 81.0 & 94.6 \\
DMPEA & 88.2 & 88.0 & $\mathbf{5 . 4}$ & &
\end{tabular}

\section{Secondary amines}

External calibration with MDMA

3-Fluorophenmetrazine

80.0

79.3

6.7

74.9

88.7

4-Methylethcathinone

84.6

83.4

4.4

80.0

89.4 


\begin{tabular}{|c|c|c|c|c|c|}
\hline 4-Methylmethamphetamine & 92.9 & 93.0 & 2.1 & 90.7 & 95.5 \\
\hline Butylone & 88.4 & 84.5 & 9.8 & 83.3 & 103.7 \\
\hline Camfetamine & 85.0 & 86.3 & 6.9 & 75.5 & 89.8 \\
\hline Ethylphenidate & 74.8 & 74.9 & 3.2 & 71.0 & 77.5 \\
\hline MBDB & 93.9 & 94.3 & 5.0 & 86.2 & 98.5 \\
\hline $\mathrm{mCPP}$ & 97.4 & 97.7 & 3.7 & 92.1 & 101.2 \\
\hline MDAI & 83.2 & 82.4 & 2.8 & 80.7 & 86.2 \\
\hline Mescaline & 92.9 & 93.4 & 3.8 & 88.0 & 97.8 \\
\hline Methiopropamine & 94.8 & 96.2 & 6.0 & 85.8 & 101.3 \\
\hline Methylone & 73.0 & 70.8 & 6.4 & 69.8 & 81.0 \\
\hline Pentedrone & 83.6 & 82.7 & 6.5 & 77.1 & 89.2 \\
\hline$\alpha$-Ethylaminopentiophenone & 97.9 & 96.3 & 5.7 & 91.6 & 105.3 \\
\hline Secondary amines mean & 87.3 & 86.8 & 5.2 & 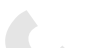 & \\
\hline \multicolumn{6}{|l|}{ Tertiary amines } \\
\hline \multicolumn{6}{|l|}{ External calibration with $\alpha$-PVP } \\
\hline 4-Fluoro- $\alpha$-PVP & 108.9 & 108.9 & 2.8 & 105.0 & 113.2 \\
\hline Cocaine & 136.2 & 136.7 & 1.3 & 133.8 & 138.3 \\
\hline Dibutylone & 106.0 & 108.8 & 8.9 & 94.2 & 117.3 \\
\hline MDDMA & 107.1 & 109.7 & 8.5 & 96.5 & 116.8 \\
\hline MDPV & 92.0 & 89.9 & 8.3 & 84.0 & 104.4 \\
\hline PV8 & 91.0 & 87.9 & 7.6 & 84.4 & 102.2 \\
\hline$\alpha-\mathrm{PHP}$ & 95.3 & 94.8 & 5.6 & 88.8 & 102.1 \\
\hline Tertiary amines mean & 105.2 & 105.2 & 6.1 & & \\
\hline Grand mean & 91.9 & 91.6 & 5.5 & & \\
\hline
\end{tabular}

${ }^{a}$ Data represents mean values from five separate experiments, each measured in duplicate

Table 2. Equimolarity and precision for stimulant-type NPS reference standards by GC-NCD at five concentration levels ${ }^{\text {. }}$.

Equimolarity $(\%)$ at specific sample concentration $(\mu \mathrm{g} / \mathrm{mL})$

Analyte

$$
40
$$

80

120

160

$200 \quad$ Mean

Primary amines

External calibration with MDMA

2C-B

$\begin{array}{ccccccc}83.3 & 75.3 & 90.1 & 85.9 & 83.0 & 83.5 & 11.2 \\ 79.2 & 76.1 & 78.5 & 71.4 & 81.9 & 77.4 & 7.6 \\ 87.0 & 85.7 & 84.6 & 82.4 & 82.8 & 84.5 & 6.2 \\ 80.5 & 100.2 & 101.3 & 105.8 & 98.7 & 97.3 & 10.8 \\ 102.8 & 93.5 & 90.4 & 87.4 & 90.1 & 92.8 & 8.2 \\ 73.2 & 72.1 & 85.3 & 78.7 & 75.5 & 77.0 & 7.7 \\ 99.6 & 91.2 & 92.0 & 91.4 & 86.9 & 92.2 & 7.7 \\ \mathbf{8 6 . 5} & \mathbf{8 4 . 9} & \mathbf{8 8 . 9} & \mathbf{8 6 . 1} & \mathbf{8 5 . 6} & \mathbf{8 6 . 4} & \mathbf{8 . 5}\end{array}$

Secondary amines 


\begin{tabular}{|c|c|c|c|c|c|c|c|}
\hline \multicolumn{8}{|c|}{ External calibration with MDMA } \\
\hline 3-Fluorophenmetrazine & 80.6 & 76.4 & 81.9 & 78.5 & 75.4 & 78.6 & 6.1 \\
\hline 4-Methylethcathinone & 84.0 & 89.3 & 88.2 & 87.3 & 88.3 & 87.4 & 6.4 \\
\hline 4-Methylmethamphetamine & 96.2 & 96.9 & 100.1 & 99.3 & 100.4 & 98.6 & 4.8 \\
\hline Butylone & 99.7 & 88.5 & 86.7 & 85.6 & 86.5 & 89.4 & 9.6 \\
\hline Camfetamine & 93.6 & 85.0 & 83.3 & 79.5 & 86.3 & 85.5 & 7.4 \\
\hline Ethylphenidate & 90.5 & 79.5 & 78.9 & 75.1 & 75.3 & 79.9 & 7.9 \\
\hline MBDB & 102.1 & 93.5 & 94.2 & 89.6 & 89.6 & 93.8 & 7.5 \\
\hline $\mathrm{mCPP}$ & 103.7 & 81.4 & 93.7 & 95.2 & 97.4 & 94.3 & 9.2 \\
\hline MDAI & 75.5 & 78.6 & 77.4 & 78.6 & 83.1 & 78.7 & 3.2 \\
\hline Mescaline & 100.0 & 95.8 & 98.2 & 99.3 & 97.6 & 98.2 & 7.5 \\
\hline Methiopropamine & 87.0 & 83.4 & 93.2 & 93.0 & 91.3 & 89.6 & 6.0 \\
\hline Methylone & 66.8 & 61.0 & 66.9 & 66.3 & 66.5 & 65.5 & 5.5 \\
\hline Pentedrone & 74.5 & 82.7 & 79.9 & 75.8 & 77.6 & 78.1 & 5.3 \\
\hline$\alpha$-Ethylaminopentiophenone & 114.2 & 104.2 & 106.9 & 101.4 & 111.9 & 107.7 & 5.4 \\
\hline Secondary amines mean & 90.6 & 85.4 & 87.8 & 86.0 & 87.7 & 87.5 & 6.6 \\
\hline Tertiary amines & - & - & - & - & - & - & - \\
\hline External calibration with $\alpha-\mathrm{P}$ & & & & & & & \\
\hline 4-Fluoro- $\alpha$-PVP & 98.0 & 95.6 & 99.9 & 101.6 & 103.8 & 99.8 & 5.2 \\
\hline Cocaine & 118.2 & 145.0 & 139.2 & 133.3 & 139.3 & 135.0 & 8.3 \\
\hline Dibutylone & 104.5 & 106.4 & 108.8 & 110.7 & 110.3 & 108.2 & 10.5 \\
\hline MDDMA & 97.5 & 103.8 & 107.6 & 106.8 & 107.6 & 104.6 & 5.3 \\
\hline MDPV & 76.7 & 74.3 & 73.4 & 86.3 & 86.4 & 79.4 & 9.0 \\
\hline PV8 & 71.1 & 68.7 & 76.3 & 80.2 & 83.3 & 75.9 & 10.8 \\
\hline$\alpha$-PHP & 80.3 & 76.4 & 82.3 & 81.5 & 87.1 & 81.5 & 9.0 \\
\hline Tertiary amines mean & 92.3 & 95.7 & 98.2 & 100.1 & 102.5 & 97.8 & 8.3 \\
\hline Grand mean & 90.0 & 87.9 & 90.7 & 89.6 & 90.9 & 89.8 & 7.5 \\
\hline
\end{tabular}

${ }^{\text {a }}$ Data represents mean values of two separate measurements per each concentration

Contrary to MS or UV detection, the $N$-equimolar response of NCD enables a uniform response to nitrogencontaining compounds regardless of analyte structure. It was shown by Yan et al. [16] that approximately 15$20 \%$ variation in equimolarity could be expected when analyzing structurally different organic nitrogen compounds, while for compounds with adjacent nitrogen atoms the signal was considerably quenched. Basically, only one nitrogen-containing external calibrator is sufficient for universal calibration by NCD, but more calibrators help control the sample preparation stage.

\subsection{Purity estimation of seized material}

The GC-NCD-APCI-QTOFMS method was used to analyze forty-two seized powdery samples previously found to contain stimulant-type NPS. The drugs were identified by HR-MS and, initially by NMR spectroscopy, prior to submitting the samples for quantitative estimation. An established single-calibrator LCCLND method [15] was used to provide a reference value for the comparison of purity values. Table 3 shows 
that the grand mean absolute difference between the purity values from the two methods was $8.1 \%$ and the range was $0.4-26.7 \%$. The absolute difference was $>20 \%$ in only two cases (brephedrone and MDPBP).

Table 3. Comparison of GC-NCD method to reference LC-CLND method for purity estimation of stimulant-type NPS in seized material ${ }^{\text {a }}$.

Analyte

Purity \% (GC-NCD) Purity \% (LC-CLND) $\quad$ Difference (\%)

\section{Primary amines}

External calibration with MDMA

$2 \mathrm{C}-\mathrm{C}$

83.7

89.1

5.4

2C-T-7

90.4

83.3

7.1

4-Fluoroamphetamine

82.7

81.0

1.7

Allylescaline

85.4

4.1

DOC

97.8

5.1

MDAI

92.7

76.4

16.8

\section{Secondary amines}

External calibration with MDMA

3,4-CTMP

3,4-DMMC

4-CEC

4-Ethylmethcathinone

4-Fluoroethylphenidate

4-Fluoromethylphenidate

4-MEAP

4-Methylbuphedrone

5-EAPB

5-MeO-MIPT

Brephedrone

Buphedrone

Clephedrone

Ethylone

HDMP-28

Mephtetramine

Methiopropamine

Methoxetamine

Methylone

$N$-Ethylhexedrone

$\mathrm{N}$-Ethylpentedrone

$N$-Ethylpentylone

Pentedrone

Thiothinone

threo-4-Methylmethylphenidate
94.4

70.1

84.0

87.1

96.3

98.3

94.8

87.8

94.8

$62.1^{\mathrm{b}}$

70.6

87.3

74.1

37.4

92.5

73.3

94.2

$58.5^{\mathrm{b}}$

92.8

99.8

101.2

101.8

104.3

91.5

93.1
90.3

82.4

87.4

86.6

96.7

86.3

92.8

75.2

93.3

78.9

94.4

71.2

84.5

30.2

94.8

63.7

81.2

71.2

85.5

90.8

104.1

101.4

88.4

74.2

91.2
4.1

12.3

3.4

0.5

0.4

12.0

2.0

12.6

1.5

16.8

23.8

16.1

10.4

7.2

2.3

9.6

13.0

12.7

7.3

9.0

2.9

0.4

15.9

17.3

1.9

\section{Tertiary amines}

External calibration with $\alpha-P V P$

4-Fluoro-PV-9 


$\begin{array}{lccr}\text { 4-Fluoro- } \alpha \text {-PVP } & 98.2 & 97.8 & 0.4 \\ \text { Cocaine } & 37.5 & 25.3 & 12.2 \\ \text { MDPBP } & 61.5 & 88.2 & 26.7 \\ \text { MDPV } & 21.6^{\mathrm{c}} & 22.9 & 1.3 \\ \text { Pyrovalerone } & 81.9 & 83.3 & 1.4 \\ \alpha \text {-PHiP } & 104.2 & 87.5 & 16.7 \\ \alpha \text {-PPP } & 76.0 & 82.1 & 6.1 \\ \alpha \text {-PVP } & 77.9 & 75.9 & 2.0 \\ \alpha \text {-PVT } & 100.3 & 101.2 & 0.9\end{array}$

\section{Grand mean}

81.0

81.0

8.1

${ }^{a}$ Purity is reported for hydrochloride $(\mathrm{HCl})$ salt as an average of two separate samplings measured in duplicate

${ }^{\mathrm{b}}$ Sample was re-measured without MBTFA using $\alpha$-PVP as external calibrator due to incomplete derivatization

${ }^{\mathrm{c}}$ Sample was re-measured using $1000 \mu \mathrm{g} / \mathrm{mL}$ working solution instead of $200 \mu \mathrm{g} / \mathrm{mL}$ to obtain well-resolved peak

\subsection{Advantages and limitations}

There are certainly alternative detectors to NCD available, which exhibit a fairly uniform response for quantification. These detectors, such as charged aerosol detector (CAD), evaporative light scattering detector (ELSD) and vacuum ultraviolet detector (VUV) were comprehensively reviewed by Zhang et al. 2019 [17]. The clear advantage of NCD over the universal detectors is its high selectivity to drugs, as only nitrogenous compounds are detected, and to top it all, this takes place in an equimolar manner. These features have allowed analysis of complex matrices, such as blood or urine, with a sufficiently high signal to noise ratio $[12,18]$. Some drugs do not contain nitrogen, and hence another technique, such as LC-CAD [19] should be considered.

The developed GC-NCD-APCI-QTOFMS method enables peak identification followed by quantitative estimation of stimulant-type NPS at an acceptable level of accuracy at least for a preliminary analysis. GC based methods are generally less amenable to quantitative analysis of polar compounds than LC -based methods. Thus the performance, in terms of equimolarity obtained by the present method for stimulants, was slightly less (91.9\%) than what was reported in a previous paper (94.4\%) by LC-CLND [15]. However, GCNCD-APCI-QTOFMS allows simultaneous peak identification with high chromatographic and mass resolution [20], which is superior to the peak purity algorithm of the UV diode array detector in the LC-CLND platform. Hence NCD-APCI-QTOFMS is capable of identifying other co-eluting constituents or impurities that could interfere with the quantification. Unfortunately, the manufacturer of CLND instrumentation has informed about discontinuation of the production of the LC version of the instrument.

Comparison of the present method to another method that shares the same principle for detection and external secondary calibration is a limitation (NCD and CLND are abbreviations given by the respective instrument manufacturers). However, our decision to choose LC-CLND as a reference method was based on the fact that neither certified primary reference standards nor validated conventional reference methods for all the NPS found in the seized samples were available to the authors. 
Apart from NMR spectroscopy [11], there has been limited research activity within forensic sciences concerning identification combined with universal quantification methods in the absence of primary reference standards. However, with MS and UV -based methods, relying only on secondary standards is risky due to compound-specific ion responses [9,21]. Importantly, there are no established guidelines for analysis in such a scenario where the primary reference standards are missing, however, we think that implementation of a statistical uncertainty model could be beneficial in such circumstances [21].

\section{Conclusions}

Lack of primary reference standards for NPS prevents their appropriate identification and quantitative purity determination by using conventional techniques. We have developed and tentatively validated a GC-NCDAPCI-QTOFMS method for the quantitative estimation of stimulant-type NPS applied to seized powdery material, using secondary reference standards for calibration. The presented method allowed purity estimation with a high average accuracy. Instant quantitative assessment of seized NPS, with the option to analyze their impurity profiles, creates valuable opportunities for quick response. However, as established forensic guidelines for analysis based only on secondary calibrators are missing, the present method serves predominantly as a rapid test producing the grounds for possible further measures. In any case, we anticipate that the present approach will find further applications to other classes of NPS as well as in other fields of forensic analysis.

CRediT authorship contribution statement

Samuel Mesihää: Conceptualization, Formal analysis, Methodology, Writing - original draft. Ilpo Rasanen: Methodology. Ilkka Ojanperä: Conceptualization, Supervision, Writing - review \& editing.

\section{References}

[1] A. Peacock, R. Bruno, N. Gisev, L. Degenhardt, W. Hall, R. Sedefov, et al., New psychoactive substances: challenges for drug surveillance, control, and public health responses, Lancet. 394 (2019) 1668-1684.

[2] European Monitoring Centre for Drugs and Drug Addiction and Europol (2019) EU Drug Markets Report 2019, Publications Office of the European Union, Luxembourg. Available at: http://www.emcdda.europa.eu/publications/joint-publications/eu-drug-markets-report-2019 (accessed January 15,2020$)$.

[3] R.P. Archer, R. Treble, K. Williams, Reference materials for new psychoactive substances, Drug Test.Anal. 3 (2011) 505-514.

[4] D. Gerostamoulos, S. Elliott, H.C. Walls, F.T. Peters, M. Lynch, O.H. Drummer, To Measure or not to Measure? That is the NPS Question, J Anal Toxicol. 40 (2016) 318-320. 
[5] J. Kinyua, N. Negreira, M. Ibanez, L. Bijlsma, F. Hernandez, A. Covaci, et al., A data-independent acquisition workflow for qualitative screening of new psychoactive substances in biological samples, Anal Bioanal Chem. 407 (2015) 8773-8785.

[6] B.L. Milman, General principles of identification by mass spectrometry, Trends Anal Chem. 69 (2015) 2433.

[7] M. Mardal, M.F. Andreasen, C.B. Mollerup, P. Stockham, R. Telving, N.S. Thomaidis, et al., HighResNPS.com: An Online Crowd-Sourced HR-MS Database for Suspect and Non-targeted Screening of New Psychoactive Substances, J Anal Toxicol. 43 (2019) 520-527.

[8] N.B. Cech, C.G. Enke, Practical implications of some recent studies in electrospray ionization fundamentals, Mass Spectrom Rev. 20 (2001) 362-387.

[9] P. Hatsis, N.J. Waters, U.A. Argikar, Implications for Metabolite Quantification by Mass Spectrometry in the Absence of Authentic Standards, Drug Metab Dispos. 45 (2017) 492-496.

[10] A. Ameline, D. Garnier, L. Gheddar, C. Richeval, J.M. Gaulier, J.S. Raul, et al., Identification and analytical characterization of seven NPS, by combination of (1)H NMR spectroscopy, GC-MS and UPLCMS/MS®, to resolve a complex toxicological fatal case, Forensic Sci Int. 298 (2019) 140-148.

[11] H.A. Naqi, S. Husbands, I.S. Blagbrough, 1H quantitative NMR and UHPLC-MS analysis of seized MDMA/NPS mixtures and tablets from night-club venues, Analytical Methods. 11 (2019) 4795-4807.

[12] S. Mesihää, I. Rasanen, A. Pelander, I. Ojanperä, Quantitative Estimation of 38 Illicit Psychostimulants in Blood by GC-APCI-QTOFMS with Nitrogen Chemiluminescence Detection Based on Three External Calibrators, J Anal Toxicol. (2019).

[13] I. Ojanperä, S. Mesihää, I. Rasanen, A. Pelander, R.A. Ketola, Simultaneous identification and quantification of new psychoactive substances in blood by GC-APCI-QTOFMS coupled to nitrogen chemiluminescence detection without authentic reference standards, Anal Bioanal Chem. 408 (2016) 33953400 .

[14] P. Meng, P. Margot, Constituent profiling of ecstasy seizures by GC-MS after joint derivatization with MSTFA and MBTFA, Forensic Toxicol. 28 (2010) 52-54.

[15] I. Rasanen, M. Kyber, I. Szilvay, J. Rintatalo, I. Ojanpera, Straightforward single-calibrant quantification of seized designer drugs by liquid chromatography-chemiluminescence nitrogen detection, Forensic Sci Int. 237 (2014) 119-125.

[16] B. Yan, J. Zhao, K. Leopold, B. Zhang, G. Jiang, Structure-dependent response of a chemiluminescence nitrogen detector for organic compounds with adjacent nitrogen atoms connected by a single bond, Anal Chem. 79 (2007) 718-726.

[17] K. Zhang, K.L. Kurita, C. Venkatramani, D. Russell, Seeking universal detectors for analytical characterizations, J Pharm Biomed Anal. 162 (2019) 192-204.

[18] S. Mesihää, I. Rasanen, I. Ojanperä, Quantitative estimation of alpha-PVP metabolites in urine by GCAPCI-QTOFMS with nitrogen chemiluminescence detection based on parent drug calibration, Forensic Sci Int. 286 (2018) 12-17.

[19] M. Popławska, A. Błażewicz, K. Kamiński, E. Bednarek, Z. Fijałek, L. Kozerski, Application of highperformance liquid chromatography with charged aerosol detection (LC-CAD) for unified quantification of 
synthetic cannabinoids in herbal blends and comparison with quantitative NMR results, Forensic Toxicol. 36 (2018) 122-140.

[20] S. Mesihää, R.A. Ketola, A. Pelander, I. Rasanen, I. Ojanperä, Development of a GC-APCI-QTOFMS library for new psychoactive substances and comparison to a commercial ESI library, Anal Bioanal Chem. 409 (2017) 2007-2013.

[21] M. Niwa, N. Nakai, S. Hosaka, T. Ishii, T. Mayumi, A. Ueda, et al., Evaluation of the uncertainty of a quantitative approach to drug metabolites in the absence of authentic standards, Bioanalysis. 12 (2020) 7-10. 